OPEN ACCESS

Edited by:

Rudolf Lucas,

Augusta University, United States

Reviewed by:

Jan Nilsson,

Lund University, Sweden

Silvia Brunelli,

University of Milano-Bicocca, Italy

*Correspondence:

Francesco Vieceli Dalla Sega vclfnc@unife.it

Specialty section:

This article was submitted to Inflammation,

a section of the journal

Frontiers in Immunology

Received: 07 February 2019 Accepted: 03 May 2019

Published: 22 May 2019

Citation:

Vieceli Dalla Sega F, Fortini F, Aquila G, Campo G, Vaccarezza $M$ and Rizzo $P$ (2019) Notch Signaling Regulates Immune Responses in Atherosclerosis

Front. Immunol. 10:1130 doi: 10.3389/fimmu.2019.01130

\section{Notch Signaling Regulates Immune Responses in Atherosclerosis}

\author{
Francesco Vieceli Dalla Sega ${ }^{1 *}$, Francesca Fortini ${ }^{1}$, Giorgio Aquila ${ }^{2}$, Gianluca Campo ${ }^{1,3}$, \\ Mauro Vaccarezza ${ }^{4}$ and Paola Rizzo ${ }^{1,5,6}$ \\ ${ }^{1}$ Translational Research Center, Maria Cecilia Hospital GVM Care \& Research, Cotignola, Italy, ${ }^{2}$ Department of Medical \\ Sciences, University of Ferrara, Ferrara, Italy, ${ }^{3}$ Cardiovascular Center, Azienda Ospedaliero-Universitaria di Ferrara, Cona, \\ Italy, ${ }^{4}$ Faculty of Health Sciences, School of Pharmacy and Biomedical Sciences, Curtin University, Perth, WA, Australia, \\ ${ }^{5}$ Department of Morphology, Surgery, and Experimental Medicine, University of Ferrara, Ferrara, Italy, ${ }^{6}$ Laboratory for \\ Technologies of Advanced Therapies, University of Ferrara, Ferrara, Italy
}

Atherosclerosis is a chronic autoimmune inflammatory disease that can cause coronary artery disease, stroke, peripheral artery disease, depending on which arteries are affected. At the beginning of atherosclerosis plasma lipoproteins accumulate in the sub-endothelial space. In response, monocytes migrate from the circulation through the endothelium into the intima where they differentiate into macrophages. These early events trigger a complex immune response that eventually involves many cellular subtypes of both innate and adaptive immunity. The Notch signaling pathway is an evolutionary conserved cell signaling system that mediates cell-to-cell communication. Recent studies have revealed that Notch modulate atherosclerosis by controlling macrophages polarization into M1 or M2 subtypes. Furthermore, it is known that Notch signaling controls differentiation and activity of T-helper and cytotoxic T-cells in inflammatory diseases. In this review, we will discuss the role of Notch in modulating immunity in the context of atherosclerosis and whether targeting Notch may represent a therapeutic strategy.

Keywords: atherosclerosis, endothelial dysfunction, Notch, DII4, immunity, M1 macrophages, T cells, GSI

\section{INTRODUCTION}

Atherosclerosis is widely recognized as the most common cause of coronary artery disease, periphery artery disease, and stroke and thus the most relevant player in mortality and morbidity in the entire world (http://www.who.int/healthinfo/global_burden_disease/estimates/en). The disease typically progresses with a slow build-up of lipid-laden plaques in large and medium arteries. It can remain silent for decades until plaque rupture or erosion leads to the formation of thrombus that blocks the arterial vessels leading to ischemic injury in the surrounding tissues. Atherosclerosis is deeply intertwined to chronic inflammation and immune cells are involved in all the stages of the disease (1). However, only recently, the CANTOS study provided definitive proof that targeting inflammation improves clinical outcomes in patients with atherosclerosis (2-4). After the success of the treatment with an anti-IL- $1 \beta$ antibody, efforts to target the immune system to counteract atherosclerosis are on the rise and potential new strategies to target immunity and inflammation are being envisioned (5). Notably, very recent data underscored the early inflammatory component of the disease in the vascular wall, with substantial arterial inflammation highly prevalent even in middle aged subjects with subclinical manifestations identified through diagnostic procedures $(6,7)$. 
The role of Notch pathway in regulating the differentiation of the different cells of innate and adaptive immune system cells is well-recognized (8). On the other hand, small molecules Notch inhibitors and specific antibodies blocking Notch ligands or receptors have provided greats tool to gain an understanding of the role of Notch in the immune system under physiological or pathological conditions (9). The Notch pathway is a major regulator of cell fate in stem cells, thus in continuously renewing tissues and its dysregulation has been observed in pathologic states, including cancer (10). Small molecules inhibiting $\gamma$ secretase (GSI, $\gamma$-secretase inhibitors), the enzyme necessary for the activation of Notch, have been originally developed because $\gamma$-secretase is also involved in a $\beta$-amyloid polypeptide, found in brains of Alzheimer's disease patients (11). During these past 20 years GSIs with different specificity and modality of action and other Notch blocking agents have been developed and are currently being investigated in clinical trials for those cancers driven by dysregulation of this pathway $(12,13)$.

In this Review, we will describe the role of Notch in the modulation of immune responses during the different phases of atherosclerosis and discuss available evidence suggesting that the targeting of this pathway may represent a novel therapeutic strategy for this disease.

\section{THE CORE NOTCH PATHWAY}

The Notch pathway is a cell signaling system that mediates cell-to-cell communication. Notch signaling controls cell fate choices and modulates crucial cellular functions, such as cell differentiation proliferation and apoptosis (14). Mammals express four isoforms of Notch receptors (Notch 1-4), and five Notch ligands [Delta-like ligand (Dll 1, 3, and 4), and Jagged-1 and 2] (15). Notch receptors are initially synthesized as a single precursor that migrates to the Golgi apparatus where it is split by a furin-like protease into an extracellular and a transmembrane subunit (16). For the assemblage of the functional receptor the two subunits are transported to the cell-membrane where they are held together by non-covalent bonds. The binding of a Notch ligand with its receptor triggers the removal of the extracellular portion, followed by two subsequent proteolytic cuts, the first by a disintegrin and metalloprotease (ADAM10 and/or 17) and the second by a $\gamma$-secretase, a multiprotein complex membrane protease, resulting in the release of the active form intracellular Notch (NICD). In the Notch "canonical" signaling the NICD migrates into the nucleus where it controls the transcription of target genes through binding to transcription factors recombinant binding protein for the immunoglobulin region $\kappa J$ (RBPJ) mediating the displacement of co-repressors and the recruitment of Mastermind proteins (MAML 1-3). The NICD/RBPJ/MAML complex recruits additional co-activators, such as p300 and PCAF to guide the transcriptional expression of the genes under the control of Notch. The best characterized Notch target genes belong to Hes (Hairy and Enhancer of Split) and Hey (Hairy and Enhancer of Split with YRPW) families of transcriptional repressors (17). The Notch signaling can also function through "non-canonical" pathways: the NICD activity can be independent of RBPJ; the activation of $\gamma$-secretase can initiate the Notch pathway independently of the binding with canonical ligand; or Notch signaling is activated in the absence of the cleavage of the $\gamma$-secretase complex (18). Non-canonical Notch signaling involves interactions with Wnt/ $\beta$-catenin (19), mTORC2 (mammalian target of rapamycin complex 2)/Akt (20), or IKK $\alpha / \beta$ (18) pathways, and can also occur in mitochondria where Notch/PINK1 (PTEN-induced kinase 1) complexes modulate mitochondrial metabolism promoting cell survival by activating the mTORC2/Akt pathway (21).

\section{THE ONSET OF ATHEROSCLEROSIS INVOLVES ENDOTHELIAL DYSFUNCTION: THE ROLE OF NOTCH}

At the onset of atherosclerosis plasma lipoproteins accumulate in the subendothelial space triggering inflammatory responses that eventually result in the expression of adhesion molecules and in the impairment of endothelial physiology. Various lines of evidence have shown that Notch signaling in ECs is dysregulated by atherogenic stimuli, such as inflammatory cytokines (2224), dyslipidemia $(25,26)$, and disturbed shear stress (2729). Conversely, it is well-established that a functional Notch signaling provides protection from endothelial dysfunction induced by various atherogenic stressors $(23,24,29)$.

Atherosclerotic lesions arise primarily in specific areas of the arteries, such as bifurcations or curvatures characterized by a turbulent blood flow and a disturbed shear stress. In recent times, data supporting a role for Notch as a transducer of laminar shear stress have been emerging (28). It has been reported that low shear stress induces the downregulation of miRNA126-5p resulting in the upregulation of Dlk1 which, by inhibiting Notch1, hinders ECs proliferation required for the efficient renewal of the endothelium damaged by dyslipidemia. Importantly, Mir126(-/-) mice exhibited exacerbated atherosclerosis (30). In agreement with this study, a reduced expression of the Notch signaling components was found in the atheroprone regions of mouse aorta (27). Moreover, in ApoE-deficient mice the modulation of shear stress with ivabradine, a heart rate reducing drug, protected the endothelium in the first phase of atherosclerosis through a mechanism depending on Notch signaling (31). Molecular mechanisms underlying the anti-atherogenetic effects of laminar shear stress through Notch have been recently described by Mack et al. (29). In this study, the lack of endothelial Notch1 results in hypercholesterolemia-induced atherosclerotic lesions in the descending aorta. Additionally, the authors have shown that, in the endothelium, Notch1 is activated by shear stress and that it is necessary for the maintenance of junctional integrity. Conversely, the reduction of Notch1 weakens endothelial junctions and causes ECs proliferation. A role of Notch in the transduction of shear stress has also been observed by Polacheck et al. that demonstrated that shear stress-induced Notch1 activation is crucial for maintaining the endothelial barrier function. In this work, findings from experiments in vivo and in an organotypic model of microvessels that could be perfused at different shear 
stress, revealed that Notch1 controls vascular barrier integrity through non-canonical signaling: shear stress triggers a Dll4dependent proteolytic activation of Notch1 that determines transmembrane domain (TMD) exposure which is required for the assembly of the endothelial junction complex (32). Recently, Miyagawa et al. showed that contacts between ECs and SMCs are necessary for the activation of Notch1 mediated by BMPR2 (bone morphogenetic protein receptor 2). In ECs, BMPR2 drives the translocation of p-JNK (phospho-c-Jun N-terminal kinase) to the cell membrane stabilizing presenilin1 and activating Notch1. Notch1 promotes ECs proliferation sustaining glucose metabolism and mitochondrial activity, and it is required for the integrity of endothelium and for its regeneration following an injury (33).

An early study in cultured cells by Quillard et al. (34) showed that TNF- $\alpha$ impairs Notch signaling by altering Notch 4 and Notch2 levels; in turn, the dysregulation of Notch pathway promotes apoptosis through the downregulation of the anti-apoptotic protein survivin (23). Interestingly, in the Quillard studies, the Notch alteration was linked with an induction of the VCAM-1 and ICAM-1 adhesion molecules. The discovery that Notch signaling downregulates the expression of adhesion molecules was subsequently confirmed and extended by Briot et al. which demonstrated that Notch signaling in the endothelium is curbed by various pro-atherogenic stimuli and that Notch1 is essential to impede the expression of inflammatory molecules and the binding of monocytes (25). In this study Notch1 was found down-regulated in aortic ECs in response to a high-fat diet or to exposure to pro-atherogenic oxidized lipids or inflammatory mediators TNF- $\alpha$ and interleukin-1 $\beta$ (IL-1 $\beta$ ). Decreased Notch1 signaling promoted inflammatory cell binding to ECs and increased expression of pro-inflammatory molecules IL-8 and CXCL1. Of note, Notch antagonized inflammatory phenotype when the protein was ectopically overexpressed in ECs exposed to stressors that cause Notch suppression (25).

Emerging evidence shows that Notch signaling mediates communication between EC and immune cells after endothelial activation induced by atherogenic stress factors. Pabois et al. have shown that TNF- $\alpha$ drives the endothelial expression of Dll4 which, in turn, promotes the polarization of macrophages to a pro-inflammatory phenotype that induces IL-6 production (35). Moreover, it was recently found that, in mice, endothelial Dll1 drives the Notch2 dependent conversion of Ly6C(hi) (inflammatory) monocytes into Ly6C(lo) (patrolling) monocytes (36). Furthermore, Krishnasamy et al. have recently reported that macrophage maturation is controlled by Dll1 expressed in ECs and requires the canonical signaling of RBPJ in macrophages, which simultaneously suppresses an inflammatory polarization of macrophages. Conversely, mice lacking Dll1 or RBPJ showed an accumulation of inflammatory macrophages resulting in compromised tissue repair and arteriogenesis (37). Interplay between ECs and macrophages has been also shown in vitro cocultures: specifically sprouting angiogenesis is enhanced in coculture of ECs with M1 polarized macrophages, but not with M2 activated macrophages, and this effect is dependent on Notch signaling (38).

\section{NOTCH REGULATES MACROPHAGES-MEDIATED INFLAMMATION IN ATHEROSCLEROSIS AND ISCHEMIC HEART DISEASE}

In the early stages of atherosclerosis circulating monocytes bind to ECs expressing adhesion proteins and migrate to the intima where they differentiate into macrophages. During the progression of atherosclerosis, monocytes attracted by inflammatory cytokines continue to infiltrate the growing plaque contributing to perpetuate the inflammation. Macrophages are classically divided into a high-inflammatory M1 subset and an anti-inflammatory (or less-inflammatory) M2 subset. M1 macrophages are classically defined as pro-inflammatory players secreting cytokines, such as IL-1, IL-6, IL-12, IL-15, IL-18, MIF, TNF- $\alpha$ able to trigger T cell-mediated responses. M2 macrophages hold anti-inflammatory activities able to resolve plaque inflammation and release different cytokines (IL-4, IL-10, and IL-13) from M1 (39). TGF- $\beta$ produced by M2 macrophages has a role in the biology of the vascular wall by influencing cell proliferation, differentiation, and production of extracellular matrix (40). Overall, inflammatory macrophages (M1) sustain mechanisms that favor atherosclerosis progression, whereas M2 macrophages drive mechanisms that are able to suppress plaque formation and progression and even to support plaque regression (39). Interestingly, the number of M1 and M2 macrophages changes depends on the plaque field. For example, M1 macrophages are abundant in regions that are inclined to rupture. On the contrary, M2 macrophages are more abundant in areas where thicker fibrous caps and smaller areas of necrosis are present, demonstrating the plaque-stabilizing function of macrophages $(41,42)$. A comprehensive discussion of macrophages' role can be found in recent reviews $(5,39)$.

Studies on cultured monocytes found that Notch1 induces M1 macrophage differentiation and heightens inflammatory responses by increasing IL-6, MCP-1, and TNF- $\alpha$ production. Conversely, Notch1 inhibition drives in the direction of an increase of M2 differentiation promoting the secretion of antiinflammatory cytokines IL-10 and IL-1RA (43, 44). Aoyama et al. have shown that in $\mathrm{ApoE}^{-/-}$mice, the treatment with Notch inhibitor DAPT reduced macrophages migratory activity and repressed ICAM-1 expression in macrophages that led to decreased macrophage infiltration in the atherosclerotic plaques (45). The first direct evidence of Notch involvement in regulating functions of human macrophages in atherosclerosis stems from a study by Fung et al. in which the authors observed the expression of Dll4 and Notch3 in infiltrating macrophages and atherosclerotic plaques. In this study, in vitro experiments with pro-inflammatory molecules, such as LPS, IL-1 $\beta$, or modified LDL have been shown to promote the expression of Dll4 in macrophages. Dll4, in turn, causes additional pro-inflammatory responses in a manner dependent on Notch receptors thereby triggering a positive feedback loop in plaque macrophages (46). Pabois et al. have shown that, during microvascular inflammation, there is an increase in the expression of Dll4 in both ECs and macrophages, suggesting that Dll4 may be 
a marker of endothelial activation and could play a role in endothelial/macrophage interactions during inflammation (35). Recently, the same group demonstrated that Dll4 is the ligand involved in the Notch-dependent selection process promoting the differentiation of M1 macrophages and preventing the differentiation of M2 macrophages blocking the expression of M2 genes induced by IL-4. Noteworthy, Dll4 was also able to promote the induction of apoptosis selectively in M2 cells (47). Consistent with a pro-inflammatory role of Notch signaling, Fukuda et al. have been shown in $\mathrm{LDLr}^{-/-}$mice that highfat/high-cholesterol diet promotes expression of Dll4 in the atherosclerotic plaques and in fat tissue. Inhibition of the Notch signaling with anti-Dll4 antibody reduced atherosclerotic lesions, diminished plaque calcification while improving insulin resistance, and decreasing fat accumulation. These changes were associated with a reduction of macrophage accumulation and decreased MCP-1 levels. In vitro experiments revealed that Dll4-mediated Notch signaling increases MCP-1 expression by activating NF- $\kappa$ B. Noteworthy, also in this setting Dll4 induced macrophages M1 polarization (48). Nakano et al. reported that in a mice model of chronic kidney disease (CKD) accumulation of the uremic toxin 3-indoxylsulfate drives the expression of Dll4 in macrophages with consequent Notch signaling-induced proinflammatory responses. In this model an anti-Dll4 antibody was able to lessen both macrophage accumulation and atherosclerosis (49). More recently, it has been shown that the inhibition of Furin, an enzyme involved in Notch1 activation (16), reduces atherosclerosis progression in $\mathrm{LDLr}^{-/-}$mice. Of note, mice treated with furin inhibitors also had reduced inflammation and less macrophages in the plaque (50).

Molecular details of the function of Notch in activated macrophages have been investigated in cultured cells. In vitro experiments found that Notch1 activation occurs in response to LPS or IFN- $\gamma$ and is implicated in macrophage activation by upregulating the expression of ICAM-1 and major histocompatibility class II antigens (MHCII) in macrophages (51). In addition, it has been shown that Notch1 positively regulates IL- 6 production via NF- $\kappa \mathrm{B}$ in activated macrophage (52). Following binding to its receptor, IL-6 activates STAT3 that, in turn, induces Dll1 expression that initiates the Notch signaling. Notch increases NF- $\kappa \mathrm{B}$ activation that results in IL-6 production which transduces stabilization of STAT3 activation establishing a positive feedback loop (53). Notch-RBPJ signaling regulates the transcription factor IRF8 to promote inflammatory macrophage polarization and expression of prototypical M1 effector molecules, such as IL-12 and iNOS (54). Conversely, blockade of canonical Notch signaling was shown to decrease macrophage-mediated inflammation correlating with improved late wound healing in diabetes (55). Recently, the role of Notch in regulating M1/M2 polarization was confirmed by Huang et al., that found that miR-148-3p is expressed following activation of Notch1 and promotes M1 polarization while inhibiting M2 differentiation (56). Furthermore, it has been reported that in $\mathrm{ApoE}^{-/-}$mice the anti-atherosclerotic miR$181 \mathrm{~b}$ modulates macrophage polarization by directly targeting Notch1 (57). Importantly, $\mathrm{Xu}$ et al. showed that Notch1 induces an increase of mitochondrial glucose oxidation that in turn triggers the expression of M1 pro-inflammatory genes (58).

Apparently in contrast with previous studies, Fondi et al. have shown that Notch is involved in polarization of M2 macrophages. In this study, it was seen that mice deficient in RBPJ in myeloid cells poorly differentiate into M2 (59). In addition, Onishi et al. have shown that Dll1 inhibits GM-CSF-dependent differentiation of monocytes into mature macrophages but promotes differentiation of dendritic cells (DCs) progenitors and further differentiation into mature DCs in the presence of GM-CSF, IL-4, and TNF- $\alpha$ (60).

It is well-established that M1 macrophages infiltration worsen ischemic damage after myocardial infarction (MI) hindering the resolution of inflammation and scar formation; by contrast, the presence of anti-inflammatory M2 macrophages in the infarct area facilitate pro-reparative processes (61). Yin et al. have shown in a rat model that after MI, M1 macrophages that infiltrate the infarct area express high levels of Notch1. The administration of the Notch inhibitor DAPT $30 \mathrm{~min}$ prior to MI caused a decrease of total macrophages in the infarct area, but enhanced the ratio of M2-activated macrophages. Furthermore, rats pretreated with DAPT had a decrease in the cardiac re-innervation after $\mathrm{MI}$, this eventually resulted in a better recovery of heart electric functionality after MI (62). The expression of the C-C chemokine receptor type 2 (CCR2) in macrophages is controlled by RPBJ (63). Recently, Bajpai et al., found that, following MI, tissue resident $\mathrm{CCR} 2^{+}$macrophages promote the recruitment of inflammatory monocytes to the injured heart. These monocytes secrete pro-inflammatory cytokines contributing to the adverse cardiac remodeling. On the contrary, resident CCR2macrophages inhibit pro-inflammatory leukocyte recruitment protecting from adverse remodeling after MI $(64,65)$.

Overall, these findings indicate that Notch signaling in monocytes and vascular macrophages promotes inflammation by facilitating a pro-inflammatory M1 phenotype at the expense of the anti-inflammatory M2 subtype. In this process, the axis Dll1Dll4/Notch1 plays a crucial role both by initiating M1 program and inhibiting M2 differentiation.

\section{FUNCTIONAL PHENOTYPES OF T-CELLS DETERMINE ATHEROSCLEROSIS PROGRESSION: A POSSIBLE ROLE OF NOTCH}

In $\mathrm{T}$ cells activation, the MHC molecules interact with oxLDL, microbial antigens, and heat shock proteins (HSP 60), which help to protect cells from stress damage driven by stressed endothelial cells. Furthermore, engagement of the co-stimulatory molecule CD28 to $\mathrm{T}$ cells allows interactions with CD80 or CD86 on antigen-presenting cells (APCs). As for monocytes/macrophages, $\mathrm{T}$ cell functional phenotypes can be modified by environmental factors and different "pabulum," thus modulating their possibility to act as regulatory or inflammatory cells.

The importance of Notch signaling in $\mathrm{T}$ cells has been established in diseases of autoimmune and inflammatory origin, but studies directly addressing the role of Notch 
in atherosclerosis are lacking. In this section, we will describe how Notch regulates the functionality of $\mathrm{T}$ cells in immune/inflammatory diseases and the putative role of Notch in modulating adaptive cells in the progression of atherosclerosis.

\section{Notch in T-Helper Cells}

Most of the $\mathrm{T}$ cells present in human plaques are CD4 Thelper (Th) cells and different T-helper cell subgroups arise following micro-environment cues and following encounter with APCs. Th1 cells secrete IFN- $\gamma$, IL-2, IL3, and TNF- $\alpha$ and have been shown to be the main subtype in human atherosclerotic plaques and the pro-atherosclerotic effect of these cells have been shown in several animal studies (1). IFN- $\gamma$ is a pro-atherogenic cytokine and growth inhibitor of SMCs and ECs that also affects macrophage polarization. After arterial damage, growth of SMCs is inhibited by IFN- $\gamma$ secreted from Th1 cells, which determines atherosclerotic plaque destabilization and rupture. Furthermore, IFN- $\gamma$ increases TNF- $\alpha$ and IL-1 production, which are strong pro-inflammatory molecules and indirectly inhibit the proliferation of SMCs and endothelial cells (66).

The capacity of Notch ligands Dll1/Dll4 to promote Th1 cell differentiation is supported by many in vitro and in vivo studies in which Notch inhibition was achieved by different approaches. Maekawa et al. have shown in cultured $\mathrm{T}$ cell that soluble Dll1 induces T-cells differentiation into IFN- $\gamma$ secreting Th1 phenotype (67). In DCs/T-cells co-culture it has been shown that Dll4-deficient DCs have limited capacity to induce CD4 T-cell activation, proliferation, and cytokines secretion (68). In mice, treatment with $\gamma$-secretase inhibitors reduced disease progression in a Th1 cell-mediated experimental autoimmune encephalomyelitis (EAE) (69) while the deletion of Dll4 from DCs resulted in a reduced ability to mount a CD4-dependent response in mice (68). Furthermore, Riella et al. have shown that Dll1 blockade results in a Th1 decrease in an allograft model (70). Interestingly, anti-Dll4 antibodies diminished T-cells secretion of IFN- $\gamma$ and TNF- $\alpha$ (71) suggesting that Delta-ligands can not only affect differentiation but also regulate cytokines secretion in differentiated Th1 cells. Studies in transgenic mice unable to activate RBPJ because of dominant-negative MAML expression, showed that canonical Notch signaling is not involved in Th1 polarization (72), and similarly, in T-cells lacking RBPJ expression, the capacity to drive a Th1 cells in response to infection was maintained (73). Dongre et al. confirmed that differentiation to Th1 cells occurs independently from RBPJ and demonstrated that Notch signaling triggers Th1 polarization by non-canonical signaling involving Notch1-dependent activation of NFкB pathway (74).

Th17 cells are characterized by the expression of ROR $\gamma \mathrm{t}$ and the production of IL-17 which have been linked to the atherosclerosis (75). Under the effect of inflammatory cytokines, Th17 cells can be switched from barrier-protective IL-10 secreting T-effector cells (T-eff) into pathogenic drivers that produce IL-22, and IFN- $\gamma$ (76). IL-1, IL-6, and IL-23 drive this Th17 switch into pathogenic effector cells. Of note, dual IL$17 /$ IFN- $\gamma$-producing Th17 cells are present in atherosclerotic human coronary arteries at a higher frequency than in the general circulation (77). In the last decade, accumulating evidence has highlighted the role of Notch in regulating differentiation and functionality of the Th17 subset. It is well-established that, in EAE, Th17 cells arise from naïve T-cells in the central nervous system where, along with Th1, promote autoimmunity (78). In this context, it has been shown that Notch inhibition, by $\gamma$ secretase inhibitors $(69,71)$ or by antibodies against Dll1 $(79)$, results in a decrease of Th1 and Th17 cells. Noteworthy, DCs expressing high levels of Dll4 have greater ability than other DCs to promote the generation of Th1 and Th17 from naïve T-cells $(80,81)$. Conversely, blocking Dll4 with antibodies decreased Notch signaling in T cells stimulated with Dll4 expressing DCs, thus reducing Th1 and Th17 cells (82). Administration of DAPT repressed Th1- and Th17-mediated responses in spleen and lymph nodes resulting in a decrease of circulating IFN- $\gamma$ and IL17 in a mouse model of arthritis (83). Meyer $\mathrm{Zu}$ Horste et al. have shown in transgenic mice that RBPJ deletion in T-cells did not impair Th17 differentiation induced by TGF- $\beta 1$ and IL- 6 . Nevertheless, in the same study, it was seen that RBPJ determines the pathogenicity of Th17 cells by regulating IL-23R and IL-10 expression (84). These findings indicate that canonical Notch signaling may modulate differentiation and cytokines secretion. Contrary to the effect observed for Delta-like- ligands, Jagged-1 suppressed Th17 cell differentiation induced by IL- 6 and TGF$\beta$ (85). Recently, Zaman et al. found that DCs lacking RBPJ promote the generation of Th17 cells but have limited capacity in instructing CD4 cells to differentiate into Tregs in the presence of TFG- $\beta$, thus suggesting that Notch signaling in DCs has a crucial role in determining balance between Th17/Tregs (86).

Th9 cells are characterized by production of IL-9, their development occurs from naive CD4 T cells in the presence of IL4 and TGF- $\beta$ (87). Some evidence suggests that IL-9 producing Th9 cells help the development of atherosclerosis (88). Elyaman et al. have reported that Jagged2, but not Dll1, induces Th9 cell polarization. Moreover, CD4 T cells lacking Notch1 and Notch2 display a reduced capacity to differentiate into Th9 when exposed to IL- 4 and TGF- $\beta$ (89).

Th2 cells are present in atherosclerotic plaques at lower frequency compared to Th1 cells. Initially, Th2 cells have been thought to act as anti-atherosclerotic by opposing Th1 phenotype (90) but subsequent studies lack clear demonstration of the atheroprotective role of Th2 cells. Engelbertsen (91) et al. reported that subjects with a high ratio of circulating Th2 cells has a lower cardiovascular disease risk, but triggering a Th2 response did not exert an anti-atherosclerotic effect in $\mathrm{ApoE}^{-/-}$ mice. Zhao et al. found that IL-4 (the main driver of Th2 differentiation) protects against atherosclerosis by promoting M2 over M1 macrophage inflammatory phenotype (92). By contrast, IL-4 delivery was not able to decrease atherosclerosis in murine models of atherosclerosis $(93,94)$.

Different lines of evidence have shown that canonical Notch signaling instructs for Th2-type response. CD4 T cells lacking RBPJ retain limited capacity to differentiate into IL-4 producing Th2-type while cells CD4 T cells deficient for Notch-1 and Notch2 completely lose the capacity to mount a Th2-type response (95). RBPJ binding sites presence on IL-4 gene enhancers regions suggests a direct role of Notch in IL-4 transcription in Th2 cells and possibly in other IL-4-secreting cells $(95,96)$. The 
capacity of Notch to control Th2 cell differentiation has been shown in many experimental models in vivo $(96,97)$. The production of specific cytokines in Th2 cells is under control of the transcription factor Gata3 (98). Notch1 and RBPJ both bind in the proximity of Gata3 promoter and the activity of this complex is required for the Notch-dependent production of IL-4, indicating that Notch controls Th2 cells differentiation and IL-4 production by directly promoting Gata3 expression $(97,99)$. In mice, expression of Jagged2 in DCs promotes Th2 cells polarization and IL-4 production by activating Notch1 canonical signaling (100). Tindemans et al. have shown in a murine model of asthma that RPJB in T-cells is necessary for the induction of a Th2-mediated allergic inflammation but, in this model, Jagged1 or Jagged2 deletion on DCs did not affect the capacity to promote a Th2 immune response (101). This may indicate that Notch signaling could be activated to induce Th2 cells also through ligands-independent pathways. Interestingly, Damle et al. found that mice with DCs lacking ADAM10 are unable to produce the cytokines necessary for Th2 differentiation but maintain the ability to drive Th1 and Th17 immunity (102). In this study, the reactivation of Notch signaling with N1ICD overexpression rescued DCs capacity to induce a Th2 response (102). This suggests that, in DCs, not only Notch ligands, but also Notch receptors, play a role in instructing Th-cells toward Th2 phenotype.

Regulatory $\mathrm{T}$ cells (Tregs) are a subpopulation of CD4 Thelper cells that modulate immunity. Regulatory T-cells hinder the differentiation of CD4 T-cells into effector subtypes and modulate APCs activity by producing modulatory cytokines, such as IL-10, IL-35, and TGF- $\beta$. It has been convincingly shown that Tregs have a protective role in atherosclerosis $(103,104)$. Human atherosclerosis is linked with low circulating Tregs (105), Tregs are also detectable in atherosclerotic plaques (106) where their number positively correlates with plaque stability (107). On the contrary, lower numbers of Tregs are correlated with a heightened infiltration of pro-inflammatory leukocytes into the plaque (108). Tregs depletion in $\mathrm{ApoE}^{-/}$mice increased atherosclerotic lesions and plaque instability $(109,110)$. Several studies, in vitro and in animal models of inflammatory diseases, found that Notch signaling increases Tregs population (111). Notch-induced Tregs have been shown to decrease severe allergic airway inflammation $(112,113)$ to prolong allograft survival (114), and to alleviate the progression of autoimmune diabetes $(115,116)$.

Importantly, atherosclerotic and hypercholesterolemic microenvironments drive Tregs cell plasticity. CD $4^{+} \mathrm{CCR}^{+}{ }^{+} \mathrm{IFN}-\gamma^{+} \mathrm{FoxP}^{+}{ }^{-}$-bet ${ }^{+}$cells (referred to as Th1-Tregs) are derived from Tregs and their presence is increased in atherosclerotic lesions of $\mathrm{ApoE}^{-/-}$mice (117). Noteworthy, Th1-Treg cells display deficient regulatory functions in vitro and impaired expression of genes linked to Treg cells immunosuppressive activity (117). Up to $40 \%$ of the $\mathrm{CD} 4 \mathrm{~T}$ cells in atherosclerotic aorta of $\mathrm{ApoE}^{-/-}$mice showed a CCR ${ }^{+} \mathrm{FoxP}^{+}{ }^{\mathrm{T}}$-bet ${ }^{+}$phenotype and secreted relevant levels of IFN- $\gamma$ and TNF- $\alpha$ (118). These cells, named FoxP $3^{+} \mathrm{CCR}^{+}{ }^{+} \mathrm{CD} 25^{-}$Teff cells by the investigators, trigger atherosclerosis in adoptive-transfer experiments and do not suppress Teff cell growth. In already established Tregs, the deletion of RPJB or Notch1 increases the ability of Tregs to suppress Th1 responses, while the ectopic expression of Notch 1 in Tregs causes an increase in Th1 activity (119). Similarly, in Tregs isolated from a mice model of autoimmune uveitis, it has been shown that Jagged1 and Dll1 downregulates Foxp3 expression limiting the immunosuppressive activity of Tregs. Conversely, antibodies against Jagged1 and Dll1 rescued Foxp3 levels. Importantly, transplantation of Tregs with Notch1 deficiency resulted in an increase in the release of inflammatory cytokines and in cellular infiltration in the uveitic eyes (120).

In summary, findings indicate that Notch sustains Tregs differentiation from progenitors, by contrast, in differentiated Tregs, Notch promotes a switch toward a pro-inflammatory phenotype.

\section{Notch in CD8 Cytotoxic T Cells}

CD8 cytotoxic T cells are activated following the binding of their T-cell receptor (TCR) to the major histocompatibility complex (MHC) expressed on APCs. CD8 cells cytotoxic activity is related to the secretion of the effector proteins perforin, granulysins, and granzymes that trigger apoptosis of target cells by forming pores on their membranes (121). In addition, CD8 $\mathrm{T}$ cells produce TNF- $\alpha$ and IFN- $\gamma$ that locally potentiate cytotoxic effect further fuelling inflammation (122). CD8 cytotoxic T cells are present in human atherosclerotic lesions, as proven decades ago (123), and their number is linked with atherosclerosis pathophysiology (124). In the plaque, CD8 T cells exacerbate inflammation, and exert cytotoxic activity toward lesion-stabilizing cells, such as smooth muscle cells and ECs, driving the atherosclerosis progression and plaque instability (125). By contrast, it must be noted that CD8 T-cell subsets with immunomodulatory capacity which limit atherosclerosis are also present in the plaque (125).

An early study by Wong et al. has found that Dlll binding to splenic CD8 T cells results in a strong decrease of IFN- $\gamma$ production with a concomitant increase of IL-10 production (126). The involvement of Notch pathway was also observed in peripheral CD8 $\mathrm{T}$ cells in which it was shown that Notch is necessary for TCR-mediated activation and that Notch inhibition blocks IFN- $\gamma$ production (127). Furthermore, it has been reported that inhibition of Notch signaling in CD8 T cells blocks the production of TNF- $\alpha$ and cytotoxic effector molecules perforin and granzyme B $(128,129)$. Noteworthy, Maekawa et al. have shown that DCs expressing high levels of Dll1, trigger in CD8 $\mathrm{T}$ cells a higher production of cytotoxic molecules. In the same study, authors observed that Notch2-deficient $\mathrm{T}$ cells poorly differentiate into cytotoxic CD8 T cells (130). Activated CD8 T cells can differentiate into terminal effector cell (TEC) or can become memory precursor cell (MPC). In CD8 T cells, the concomitant Notch1 and Notch2 deficiency, or the lack of RBPJ, reduced TEC differentiation resulting in defects in host defense and eradication of tumors (131). Taken together these results suggest that Notch activates CD8 T cells at different levels. Notch signaling in CD8 $\mathrm{T}$ cells promotes the cytotoxic activity of the effector cells, in addition Notch instructs CD8 T cells toward TEC differentiation. 


\section{NOTCH MODULATION OF THE CROSSTALK BETWEEN INNATE AND ACQUIRED IMMUNITY MAY CONTROL ATHEROSCLEROSIS PROGRESSION}

DCs constitute a bridge between the innate and the adaptive immunity and the role of Notch signaling as mediator of communication between DCs and T-cells has been extensively investigated (132). As previously described, DCs express Notch ligands Dll1, Dll4, Jagged-1, Jagged-2, while T-cells express Notch receptors. The Notch ligand-receptor associations in DCs/Th initiate the differentiation program toward a specific $\mathrm{T}$ cell functional phenotype (95). For instance, it has been shown that DCs expressing Dll1 or Dll4 promote the differentiation toward pro-atherosclerotic Th1 $(68,69,82)$. On the contrary, Jagged ligands instruct $\mathrm{T}$ cells toward the less inflammatory $\mathrm{Th} 2$ and $\mathrm{Th} 9$ subtype (132).

Myeloid-derived suppressor cells (MDSCs) constitute a heterogeneous population of immature myeloid cells that originate in the bone marrow during inflammatory diseases and migrate to inflamed tissue where they strongly suppress T-cell responses in autoimmunity (133). Recently, the murine MDSCs subset CD11b+Gr1+ has been found to possess antiatherosclerotic activity in $\mathrm{LDLr}^{-/-}$mice as MDSC adoptive transfer in these animals decreased the number and activity of Th1 and Th17 cells in the plaque and reduced the atherosclerotic lesions (134). Acute coronary syndrome (ACS) patients displayed expansion of MDSC population identified as CD14+HLA-DR/low that when isolated from ACS patients MDSCs were found to contrast T-cell proliferation and IFN- $\gamma$ production in vitro more efficiently compared to MDSC isolated from healthy or stable angina subjects (135). Transgenic mice overexpressing ADAM10, an enzyme involved in the activation of Notch, displayed a systemic expansion of $\mathrm{CD}_{11} \mathrm{~b}^{+} \mathrm{Gr} 1^{+}$MDSCs (136). Conversely, blockage of Jagged1 and Jagged2 in MDSCs have been shown to inhibit T-cell repression activity of these cells (137). In light of these findings, the role of Notch in modulating the interactions between innate and adaptive immunity, may be also relevant in the progression of atherosclerosis as already seen in cancer (138). However, it must be noted that the role of Notch signaling in MDSCs has been mainly studied in the context of cancer and there is still a lot to be understood about these cells. For a comprehensive and critical discussion of the role of Notch in MDSCs we refer the reader to the following references $(111,138,139)$.

\section{CONCLUSIVE REMARKS AND CLINICAL PERSPECTIVES}

Atherosclerosis is a chronic inflammatory disease driven by a complex interplay between vascular and immune cells, with an involvement of the Notch signaling pathway in each phase of the disease. Activation of Notch promotes atherosclerosis by inducing a pro-inflammatory M1 phenotype in macrophages

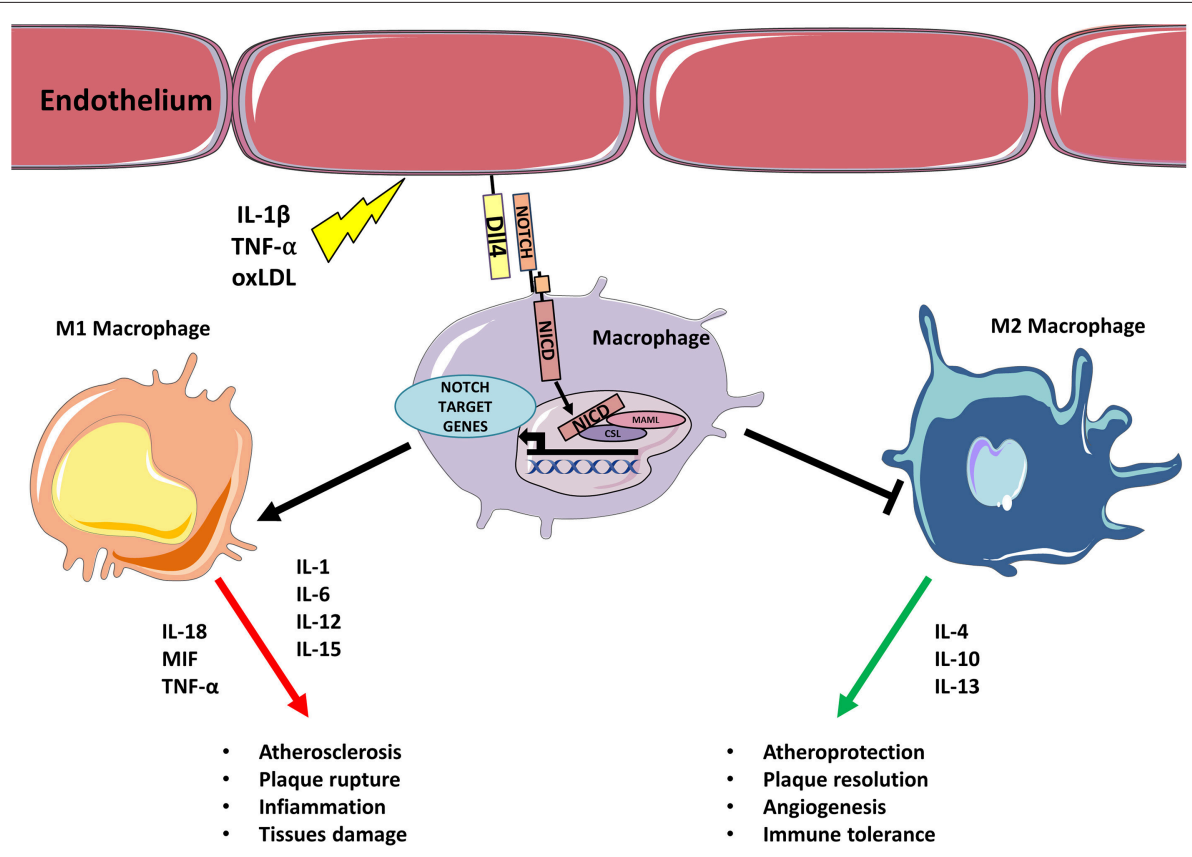

FIGURE 1 | Inflammatory stimulus triggers M1 polarization via Notch. Inflammatory stimulus, such as IL-1 $\beta$, TNF- $\alpha$, oxLDL upregulates DII4 on endothelial cells (or APCs). Binding between endothelial DII4 (and possibly DII1) and Notch1 or Notch3 in macrophages initiates Notch program that results in macrophages M1 polarization and concomitant inhibition of M2 differentiation. M1 activated macrophages feed inflammation and atherosclerosis by secreting further inflammatory cytokines, Notch blocks M2 polarization inhibiting M2 capacity to resolve inflammation/lesion. 
at the expense of the M2 anti-inflammatory subtype. Even if the detailed molecular mechanisms are still not completely known, solid evidence has shown that the Dll4/Notch1 axis is pivotal in favoring M1 polarization, while blocking M2 immunosuppressive macrophages and their cytokines (Figure 1). $\mathrm{T}$ cells in atherosclerotic plaques can either promote-or protect from-the onset and progression of atherosclerosis. Notch ligands Dll1, Dll4, Jagged1, Jagged2 on APCS interact with Notch receptors on T-cells and this interaction regulate their differentiation. APCs expressing Dll1 or Dll4 promote the differentiation toward pro-atherosclerotic Th1 whereas Jagged ligands instruct $\mathrm{T}$ cells toward the less inflammatory Th2 subtype. Jagged also mediates the inhibitory activity of MDSCs on CD4 and CD8 T-cells (137). Notch signaling is also necessary for Tregs differentiation from naïve $\mathrm{T}$ cells, however, in already established Tregs Notch mediates the differentiation toward a Th1-like inflammatory phenotype (111). Although clear evidence demonstrates both the involvement of $\mathrm{T}$ cells in atherosclerosis and of Notch signaling in $\mathrm{T}$ cell regulation, the specific role played by the Notch signaling in $\mathrm{T}$ cells in the context of atherosclerosis has not been directly investigated. Based on the findings discussed in this review, it appears likely that Notch may favor atherosclerosis by promoting Th and CD8 cells formation (Figure 2). Consequently, inhibition of the Notch pathway could be a novel strategy to counteract inflammation of the vascular wall, and thus atherosclerosis, by interfering with the production of cytokines from M1 macrophages and with Th1 cells infiltration in the plaque. In principle, this strategy could have the advantage of increasing the immunomodulatory activity of M2 macrophages without depleting anti-inflammatory Tregs in the plaque.

Notch inhibition for cancer and other indications has been so far mainly relying on GSIs. GSIs are a heterogeneous group of small molecules that prevent Notch cleavage by the $\gamma$-secretase enzymatic complex, thus reducing the levels of active Notch

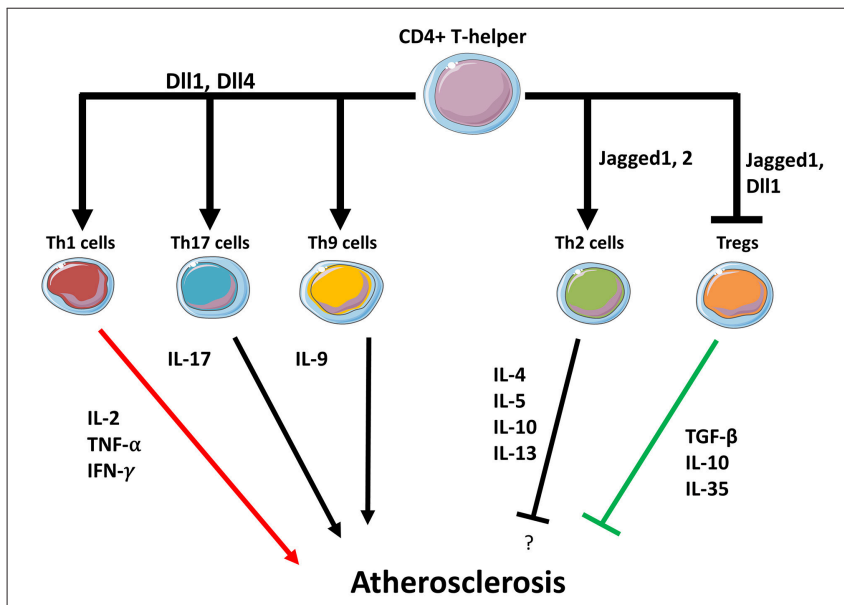

FIGURE 2 | Notch may regulate T helper cells fate in the plaque. DII1 and DII4 ligands expressed in APCs promote Th1, Th9, and Th17 differentiation while suppressing Th2 differentiation. Jagged1 induces Th2 differentiation. DIl1 and Jagged1 both suppress Tregs activity.
(140). GSIs were developed based on their activity on Notch1 but can also inhibit, depending on the cell type, the cleavage of other Notch paralogs or interfere with other pathways $(11,13)$. Currently, there are several GSIs being investigated in Phase I and/or II clinical trials in cancer patients (clinicaltrials.gov). Specific drug administration approaches are required to limit their main toxic effect which is intestinal toxicity (141). Studies in vivo have shown that GSIs are able to interfere with the progression of atherosclerosis. Systemic administration of GSI (LY411,575 0.2, and $1.0 \mathrm{mg} / \mathrm{kg} /$ day for 8-weeks) suppressed Notch signaling in ApoE-deficient mice fed a high fat diet and reduced total plaque areas in the aortic sinus, plus macrophages from these mice showed reduced levels of ICAM-1 and migration ability. $0.2 \mathrm{mg} / \mathrm{kg} /$ day did not cause loss weight and alterations of intestine and thymus whereas with the $1 \mathrm{mg} / \mathrm{kg} / \mathrm{day}$ dose intestinal and immunologic toxicity was observed, suggesting that only low doses of GSI could be used long term without adverse effects (45). Based on these results, GSI treatment in patients with atherosclerosis could dampen the inflammatory activities of macrophages; the overall effects on atherosclerosis progression would depend on how the treatment affects the complex interplay between acquired and innate immunity, and thus, the balance between pro- or anti-atherosclerotic $\mathrm{T}$ cells. For precise targeting of macrophages, mesoporous silica nanoparticles containing GSIs could be used to specifically deliver these molecules to these cells (142). Alternatively, cellspecific delivery to macrophages of Notch inhibitors miRNAs (143) using siRNA loaded exosomes could be another specific approach to block Notch and inflammation in these cells $(49,144)$. GSIs-coated stents could be used to prevent reocclusion in some patients, after percutaneous intervention, since Notch could be also involved in restenosis due to its effect on promotion of vascular smooth muscle cells proliferation (145). Of interest, a recent study has shown that sulindac, a nonsteroidal anti-inflammatory drug, interferes with triple negative breast cancer growth by inhibiting Notch in cancer stem cells without inhibiting Notch expression or cleavage in murine T cells (146). Based on these findings, it would be of interest to test the effect of this drug in the context of atherosclerosis, specifically in the regulation of Notch signaling in macrophages.

A clear understanding of the role played by each receptor and/or ligand in each cell of the innate and acquired immune system involved in atherosclerosis could lead to a more precise targeting of the Notch signaling by antibody-mediated blocking of a specific component of the pathway. Blocking antibodies against Dll4, Notch1, Notch2, or Notch3 are already being tested in phase I clinical trials in cancer patients (9). An antiDll4 antibody has been employed to successfully interfere with vascular inflammation and atherosclerosis progression in a mice model of atherosclerosis (48). Our data in peripheral artery disease (PAD) patients showing that intraplaque levels of Dll4 mRNA could be associated with the progression of the disease suggest that PAD patients could also benefit of this approach (147). Given the widespread expression of Dll4 in the vasculature and the immune system, concerns about toxicity of the treatment have been addressed. Long term administration (12 weeks) of agents blocking Dll4 in mice caused no toxicity in one study 
(48) whereas Yam et al. reported adverse effects in the liver (148). In cancer patients, administration of anti-Dll4 antibody caused heart failure in a subset of patients (149). Differently from Dll4, in the context of atherosclerosis Jagged1-mediated signaling could be protective, since anti-Jagged 1 immunotherapy has been shown to inhibit MDSCs and overcome tumor-induced tolerance by activating T-cell (137). Consistently, high levels of Jagged1 mRNA intraplaque were associated to a less inflamed plaque profile and a slower progression of disease in PAD patients (147).

Clinical trials employing Tregs are ongoing in organ transplantation, type I diabetes, and graft vs. host disease. These trials mainly used naturally occurring FoxP $3^{+}$Tregs from patients, followed by in vitro expansion and reinfusion. Of note, adoptive transfer of Tregs in mice models reduced atherosclerosis considerably, suggesting that a similar strategy may be beneficial in patients (150). On light of this, targeting of Notch pathway could be utilized to improve the generation and specificity of T-cells for adoptive transplant immunotherapies as already proposed for cancer-immunotherapy (151).

As discussed in previous paragraphs, the first step of atherosclerosis involves the interplay between the endothelium and infiltrating immune cells, step in which Notch1 in particular plays a crucial role by preventing the expression of adhesion molecules on ECs. Strategies aimed to prevent a reduction of Notch1 caused by turbulent shear stress (31) or dyslipidemia (25) or low estrogen conditions, as in post-menopausal women or breast cancer patients treated with anti-estrogens (152) could reduce endothelial dysfunction and therefore, plaque formation in atheroprone areas of the aortic endothelium. Heart rate reducing drugs (31), miRNA (30), or specific estrogen receptor

\section{REFERENCES}

1. Gisterå A, Hansson GK. The immunology of atherosclerosis. Nat Rev Nephrol. (2017) 13:368-80. doi: 10.1038/nrneph.2017.51

2. Ridker PM, Everett BM, Thuren T, MacFadyen JG, Chang WH, Ballantyne C, et al. Antiinflammatory therapy with canakinumab for atherosclerotic disease. N Engl J Med. (2017) 377:1119-31. doi: 10.1056/NEJMoa1707914

3. Vaccarezza M, Balla C, Rizzo P. Atherosclerosis as an inflammatory disease: doubts? no more. Int J Cardiol Heart Vasc. (2018) 19:1-2. doi: 10.1016/j.ijcha.2018.03.003

4. Libby P, Hansson GK. Taming immune and inflammatory responses to treat atherosclerosis. J Am Coll Cardiol. (2018) 71:173-6. doi: 10.1016/j.jacc.2017.10.081

5. Zhao TX, Mallat Z. Targeting the immune system in atherosclerosis: JACC state-of-the-art review. J Am Coll Cardiol. (2019) 73:1691-706. doi: $10.1016 /$ j.jacc.2018.12.083

6. Fernández-Friera L, Fuster V, López-Melgar B, Oliva B, Sánchez-González J, Macías A, et al. Vascular inflammation in subclinical atherosclerosis detected by hybrid PET/MRI. J Am Coll Cardiol. (2019) 73:1371-82. doi: 10.1016/j.jacc.2018.12.075

7. Blankstein R, Libby P, Bhatt DL. Arterial inflammation: the heat before the storm. J Am Coll Cardiol. (2019) 73:1383-5. doi: 10.1016/j.jacc.2019.02.002

8. Radtke F, MacDonald HR, Tacchini-Cottier F. Regulation of innate and adaptive immunity by Notch. Nat Rev Immunol. (2013) 13:427-37. doi: $10.1038 /$ nri3445

9. Janghorban M, Xin L, Rosen JM, Zhang XH. Notch signaling as a regulator of the tumor immune response: to target or not to target? Front Immunol. (2018) 9:1649. doi: 10.3389/fimmu.2018.01649 agonist (24) could be used to prevent Notch1 downregulation in these areas.

The CANTOS study provided definitive prove that tackling inflammation by blocking IL-1 $\beta$ with the monoclonal antibody canakinumab can be a successful strategy to reduce atherosclerosis progression (2). It should be noted that canakinumab efficacy depends on the reduction of inflammation achieved. Individuals with hsCRP concentrations $<2 \mathrm{mg} / \mathrm{L}$ experienced a $25 \%$ reduction in cardiovascular events compared to a non-significant $5 \%$ reduction in those with on-treatment hsCRP levels $\geq 2 \mathrm{mg} / \mathrm{L}$ (153). Similarly, blocking IL-6 by a specific antibody has shown a protective effect in atherosclerosis even though the results of this treatment are still unclear (5). Targeting Notch in immune cells could represent a novel approach to counteract inflammation and thus atherosclerosis. To this aim a deeper knowledge of the specific roles of each Notch receptor and ligand in innate and adaptive immune cells, in the context of atherosclerosis, is needed.

\section{AUTHOR CONTRIBUTIONS}

FV, MV, and PR wrote the paper. GC, GA, and FF provided substantial revision. All authors reviewed and approved the final version of the manuscript.

\section{ACKNOWLEDGMENTS}

We thank Prof. Antonio Pannuti for the critical reading of the manuscript and for his valuable suggestions.

10. Espinoza I, Miele L. Notch inhibitors for cancer treatment. Pharmacol Ther. (2013) 139:95-110. doi: 10.1016/j.pharmthera.2013.02.003

11. Golde TE, Koo EH, Felsenstein KM, Osborne BA, Miele L. $\gamma$-secretase inhibitors and modulators. Biochim Biophys Acta. (2013) 1828:2898-907. doi: 10.1016/j.bbamem.2013.06.005

12. Tamagnone L, Zacchigna S, Rehman M. Taming the Notch transcriptional regulator for cancer therapy. Molecules. (2018) 23. doi: 10.3390/molecules23020431

13. Ran Y, Hossain F, Pannuti A, Lessard CB, Ladd GZ, Jung JI, et al. $\gamma$-secretase inhibitors in cancer clinical trials are pharmacologically and functionally distinct. EMBO Mol Med. (2017) 9:950-66. doi: 10.15252/emmm.201607265

14. Siebel C, Lendahl U. Notch signaling in development, tissue homeostasis, and disease. Physiol Rev. (2017) 97:1235-94. doi: 10.1152/physrev.00005.2017

15. Bray SJ. Notch signalling: a simple pathway becomes complex. Nat Rev Mol Cell Biol. (2006) 7:678-89. doi: 10.1038/nrm2009

16. Logeat F, Bessia C, Brou C, LeBail O, Jarriault S, Seidah NG, et al. The Notch1 receptor is cleaved constitutively by a furin-like convertase. Proc Natl Acad Sci USA. (1998) 95:8108-12. doi: 10.1073/pnas.95.14.8108

17. Kovall RA, Gebelein B, Sprinzak D, Kopan R. The canonical Notch signaling pathway: structural and biochemical insights into shape, sugar, and force. Dev Cell. (2017) 41:228-41. doi: 10.1016/j.devcel.2017.04.001

18. Ayaz F, Osborne BA. Non-canonical Notch signaling in cancer and immunity. Front Oncol. (2014) 4:345. doi: 10.3389/fonc.2014.00345

19. Corada M, Nyqvist D, Orsenigo F, Caprini A, Giampietro C, Taketo MM, et al. The Wnt/beta-catenin pathway modulates vascular remodeling and specification by upregulating Dll4/Notch signaling. Dev Cell. (2010) 18:93849. doi: 10.1016/j.devcel.2010.05.006 
20. Perumalsamy LR, Nagala M, Banerjee P, Sarin A. A hierarchical cascade activated by non-canonical Notch signaling and the mTOR-rictor complex regulates neglect-induced death in mammalian cells. Cell Death Differ. (2009) 16:879-89. doi: 10.1038/cdd.2009.20

21. Lee KS, Wu Z, Song Y, Mitra SS, Feroze AH, Cheshier SH, et al. Roles of PINK1, mTORC2, and mitochondria in preserving brain tumor-forming stem cells in a noncanonical Notch signaling pathway. Genes Dev. (2013) 27:2642-7. doi: 10.1101/gad.225169.113

22. Pannella M, Caliceti C, Fortini F, Aquila G, Vieceli Dalla Sega F, Pannuti A, et al. Serum from advanced heart failure patients promotes angiogenic sprouting and affects the Notch pathway in human endothelial cells. J Cell Physiol. (2016) 231:2700-10. doi: 10.1002/jcp.25373

23. Quillard T, Devallière J, Coupel S, Charreau B. Inflammation dysregulates Notch signaling in endothelial cells: implication of Notch2 and Notch4 to endothelial dysfunction. Biochem Pharmacol. (2010) 80:2032-41. doi: 10.1016/j.bcp.2010.07.010

24. Fortini F, Vieceli Dalla Sega F, Caliceti C, Aquila G, Pannella M, Pannuti A, et al. Estrogen receptor $\beta$-dependent Notch 1 activation protects vascular endothelium against tumor necrosis factor $\alpha(\mathrm{TNF} \alpha)$-induced apoptosis. $J$ Biol Chem. (2017) 292:18178-91. doi: 10.1074/jbc.M117.790121

25. Briot A, Civelek M, Seki A, Hoi K, Mack JJ, Lee SD, et al. Endothelial Notch1 is suppressed by circulating lipids and antagonizes inflammation during atherosclerosis. J Exp Med. (2015) 212:2147-63. doi: 10.1084/jem.20150603

26. Briot A, Bouloumié A, Iruela-Arispe ML. Notch, lipids, and endothelial cells. Curr Opin Lipidol. (2016) 27:513-20. doi: 10.1097/MOL.0000000000000337

27. Aquila G, Morelli M, Nigro P, Pannuti A, Pinton P, Bonora M, et al. Study of Notch signaling modulation by shear stress by using an ex vivo cone-andplate system. Vasc Pharmacol. (2015) 75:41. doi: 10.1016/j.vph.2015.11.005

28. Vieceli Dalla Sega F, Aquila G, Fortini F, Vaccarezza M, Secchiero P, Rizzo $\mathrm{P}$, et al. Context-dependent function of ROS in the vascular endothelium: the role of the Notch pathway and shear stress. Biofactors. (2017) 43:475-85. doi: 10.1002/biof.1359

29. Mack JJ, Mosqueiro TS, Archer BJ, Jones WM, Sunshine H, Faas GC, et al. Notch1 is a mechanosensor in adult arteries. Nat Commun. (2017) 8:1620. doi: 10.1038/s41467-017-01741-8

30. Schober A, Nazari-Jahantigh M, Wei Y, Bidzhekov K, Gremse F, Grommes J, et al. MicroRNA-126-5p promotes endothelial proliferation and limits atherosclerosis by suppressing Dlk1. Nat Med. (2014) 20:368-76. doi: $10.1038 / \mathrm{nm} .3487$

31. Aquila G, Morelli MB, Vieceli Dalla Sega F, Fortini F, Nigro P, Caliceti C, et al. (2018). Heart rate reduction with ivabradine in the early phase of atherosclerosis is protective in the endothelium of ApoE-deficient mice. $J$ Physiol Pharmacol. 69:35-52. doi: 10.26402/jpp.2018.1.04

32. Polacheck WJ, Kutys ML, Yang J, Eyckmans J, Wu Y, Vasavada H, et al. A non-canonical Notch complex regulates adherens junctions and vascular barrier function. Nature. (2017) 552:258-62. doi: 10.1038/nature24998

33. Miyagawa K, Shi M, Chen PI, Hennigs JK, Zhao Z, Wang M, et al. Smooth muscle contact drives endothelial regeneration by BMPR2-Notch1mediated metabolic and epigenetic changes. Circ Res. (2019) 124:211-24. doi: 10.1161/circresaha.118.313374

34. Quillard T, Devalliere J, Chatelais M, Coulon F, Séveno C, Romagnoli M, et al. Notch2 signaling sensitizes endothelial cells to apoptosis by negatively regulating the key protective molecule survivin. PLoS ONE. (2009) 4:e8244. doi: 10.1371/journal.pone.0008244

35. Pabois A, Pagie S, Gérard N, Laboisse C, Pattier S, Hulin P, et al. Notch signaling mediates crosstalk between endothelial cells and macrophages via Dll4 and IL6 in cardiac microvascular inflammation. Biochem Pharmacol. (2016) 104:95-107. doi: 10.1016/j.bcp.2016.01.016

36. Gamrekelashvili J, Giagnorio R, Jussofie J, Soehnlein O, Duchene J, Briseño CG, et al. Regulation of monocyte cell fate by blood vessels mediated by Notch signalling. Nat Commun. (2016) 7:12597. doi: 10.1038/ncomms12597

37. Krishnasamy K, Limbourg A, Kapanadze T, Gamrekelashvili J, Beger $\mathrm{C}$, Häger C, et al. Blood vessel control of macrophage maturation promotes arteriogenesis in ischemia. Nat Commun. (2017) 8:952. doi: 10.1038/s41467-017-00953-2

38. Tattersall IW, Du J, Cong Z, Cho BS, Klein AM, Dieck CL, et al. In vitro modeling of endothelial interaction with macrophages and pericytes demonstrates Notch signaling function in the vascular microenvironment. Angiogenesis. (2016) 19:201-15. doi: 10.1007/s10456-016-9501-1

39. Tabas I, Lichtman AH. Monocyte-macrophages and $\mathrm{T}$ cells in atherosclerosis. Immunity. (2017) 47:621-34. doi: 10.1016/j.immuni. 2017.09.008

40. Grainger DJ. TGF-beta and atherosclerosis in man. Cardiovasc Res. (2007) 74:213-22. doi: 10.1016/j.cardiores.2007.02.022

41. Peled M, Fisher EA. Dynamic aspects of macrophage polarization during atherosclerosis progression and regression. Front Immunol. (2014) 5:579. doi: 10.3389/fimmu.2014.00579

42. Smigiel KS, Parks WC. Matrix metalloproteinases and leukocyte activation. Prog Mol Biol Transl Sci. (2017) 147:167-95. doi: 10.1016/bs.pmbts.2017.01.003

43. Singla RD, Wang J, Singla DK. Regulation of Notch 1 signaling in THP- 1 cells enhances M2 macrophage differentiation. Am J Physiol Heart Circ Physiol. (2014) 307:H1634-42. doi: 10.1152/ajpheart.00896.2013

44. Singla DK, Wang J, Singla R. Primary human monocytes differentiate into M2 macrophages and involve Notch-1 pathway. Can J Physiol Pharmacol. (2017) 95:288-94. doi: 10.1139/cjpp-2016-0319

45. Aoyama T, Takeshita K, Kikuchi R, Yamamoto K, Cheng XW, Liao JK, et al. gamma-secretase inhibitor reduces diet-induced atherosclerosis in apolipoprotein E-deficient mice. Biochem Biophys Res Commun. (2009) 383:216-21. doi: 10.1016/j.bbrc.2009.03.154

46. Fung E, Tang SM, Canner JP, Morishige K, Arboleda-Velasquez JF, Cardoso AA, et al. Delta-like 4 induces Notch signaling in macrophages: implications for inflammation. Circulation. (2007) 115:2948-56. doi: 10.1161/CIRCULATIONAHA.106.675462

47. Pagie S, Gérard N, Charreau B. Notch signaling triggered via the ligand DLL4 impedes M2 macrophage differentiation and promotes their apoptosis. Cell Commun Signal. (2018) 16:4. doi: 10.1186/s12964-017-0214-x

48. Fukuda D, Aikawa E, Swirski FK, Novobrantseva TI, Kotelianski V, Gorgun $\mathrm{CZ}$, et al. Notch ligand delta-like 4 blockade attenuates atherosclerosis and metabolic disorders. Proc Natl Acad Sci USA. (2012) 109:E1868-77. doi: 10.1073/pnas.1116889109

49. Nakano T, Katsuki S, Chen M, Decano JL, Halu A, Lee LH, et al. Uremic toxin indoxyl sulfate promotes proinflammatory macrophage activation via the interplay of OATP2B1 and Dll4-Notch signaling. Circulation. (2019) 139:78-96. doi: 10.1161/CIRCULATIONAHA.118.034588

50. Yakala GK, Cabrera-Fuentes HA, Crespo-Avilan GE, Rattanasopa C, Burlacu A, George BL, et al. FURIN inhibition reduces vascular remodeling and atherosclerotic lesion progression in mice. Arterioscler Thromb Vasc Biol. (2019) 39:387-409. doi: 10.1161/ATVBAHA.118.311903

51. Monsalve E, Pérez MA, Rubio A, Ruiz-Hidalgo MJ, Baladrón V, GarcíaRamírez JJ, et al. Notch-1 up-regulation and signaling following macrophage activation modulates gene expression patterns known to affect antigenpresenting capacity and cytotoxic activity. J Immunol. (2006) 176:5362-73. doi: 10.4049/jimmunol.176.9.5362

52. Wongchana W, Palaga T. Direct regulation of interleukin-6 expression by Notch signaling in macrophages. Cell Mol Immunol. (2012) 9:155-62. doi: $10.1038 / \mathrm{cmi} .2011 .36$

53. Hildebrand D, Uhle F, Sahin D, Krauser U, Weigand MA, Heeg K. The interplay of Notch signaling and STAT3 in TLR-activated human primary monocytes. Front Cell Infect Microbiol. (2018) 8:241. doi: 10.3389/fcimb.2018.00241

54. Xu H, Zhu J, Smith S, Foldi J, Zhao B, Chung AY, et al. NotchRBP-J signaling regulates the transcription factor IRF8 to promote inflammatory macrophage polarization. Nat Immunol. (2012) 13:642-50. doi: 10.1038/ni.2304

55. Kimball AS, Joshi AD, Boniakowski AE, Schaller M, Chung J, Allen R, et al. Notch regulates macrophage-mediated inflammation in diabetic wound healing. Front Immunol. (2017) 8:635. doi: 10.3389/fimmu.2017.00635

56. Huang F, Zhao JL, Wang L, Gao CC, Liang SQ, An DJ, et al. miR-148a-3p mediates Notch signaling to promote the differentiation and M1 activation of macrophages. Front Immunol. (2017) 8:1327. doi: 10.3389/fimmu.2017.01327

57. An TH, He QW, Xia YP, Chen SC, Baral S, Mao L, et al. MiR$181 \mathrm{~b}$ antagonizes atherosclerotic plaque vulnerability through modulating 
macrophage polarization by directly targeting Notch1. Mol Neurobiol. (2017) 54:6329-41. doi: 10.1007/s12035-016-0163-1

58. Xu J, Chi F, Guo T, Punj V, Lee WN, French SW, et al. NOTCH reprograms mitochondrial metabolism for proinflammatory macrophage activation. $J$ Clin Invest. (2015) 125:1579-90. doi: 10.1172/JCI76468

59. Foldi J, Shang Y, Zhao B, Ivashkiv LB, Hu X. RBP-J is required for M2 macrophage polarization in response to chitin and mediates expression of a subset of M2 genes. Protein Cell. (2016) 7:201-9. doi: 10.1007/s13238-016-0248-7

60. Ohishi K, Varnum-Finney B, Serda RE, Anasetti C, Bernstein ID. The Notch ligand, delta-1, inhibits the differentiation of monocytes into macrophages but permits their differentiation into dendritic cells. Blood. (2001) 98:1402-7. doi: 10.1182/blood.V98.5.1402

61. ter Horst EN, Hakimzadeh NAM, van der Laan Krijnen PA, Niessen HW, Piek JJ. Modulators of macrophage polarization influence healing of the infarcted myocardium. Int J Mol Sci. (2015) 16:29583-91. doi: 10.3390/ijms161226187

62. Yin J, Hu H, Li X, Xue M, Cheng W, Wang Y, et al. Inhibition of Notch signaling pathway attenuates sympathetic hyperinnervation together with the augmentation of M2 macrophages in rats post-myocardial infarction. Am J Physiol Cell Physiol. (2016) 310:C41-53. doi: 10.1152/ajpcell.00163.2015

63. Palaga T, Wongchana W, Kueanjinda P. Notch signaling in macrophages in the context of cancer immunity. Front Immunol. (2018) 9:652. doi: $10.3389 /$ fimmu.2018.00652

64. Chen B, Brickshawana A, Frangogiannis NG. The functional heterogeneity of resident cardiac macrophages in myocardial injury. Circ Res. (2019) 124:183-5. doi: 10.1161/CIRCRESAHA.118.314357

65. Bajpai G, Bredemeyer A, Li W, Zaitsev K, Koenig AL, Lokshina I, et al. Tissue resident CCR2- and CCR2+ cardiac macrophages differentially orchestrate monocyte recruitment and fate specification following myocardial injury. Circ Res. (2019) 124:263-78. doi: 10.1161/CIRCRESAHA.118.314028

66. Libby P, Ridker PM, Maseri A. Inflammation and atherosclerosis. Circulation. (2002) 105:1135-43. doi: 10.1161/hc0902.104353

67. Maekawa Y, Tsukumo S, Chiba S, Hirai H, Hayashi Y, Okada H, et al. Delta1Notch3 interactions bias the functional differentiation of activated CD4+ T cells. Immunity. (2003) 19:549-59. doi: 10.1016/S1074-7613(03)00270-X

68. Laky K, Evans S, Perez-Diez A, Fowlkes BJ. Notch signaling regulates antigen sensitivity of naive CD4+ T cells by tuning co-stimulation. Immunity. (2015) 42:80-94. doi: 10.1016/j.immuni.2014.12.027

69. Minter LM, Turley DM, Das P, Shin HM, Joshi I, Lawlor RG, et al. Inhibitors of gamma-secretase block in vivo and in vitro T helper type 1 polarization by preventing Notch upregulation of Tbx21. Nat Immunol. (2005) 6:680-8. doi: 10.1038/ni1209

70. Riella LV, Ueno T, Batal I, De Serres SA, Bassil R, Elyaman W, et al. Blockade of Notch ligand $\delta 1$ promotes allograft survival by inhibiting alloreactive Th1 cells and cytotoxic T cell generation. J Immunol. (2011) 187:4629-38. doi: 10.4049/jimmunol.1004076

71. Jurynczyk M, Jurewicz A, Raine CS, Selmaj K. Notch3 inhibition in myelin-reactive $\mathrm{T}$ cells down-regulates protein kinase $\mathrm{C}$ theta and attenuates experimental autoimmune encephalomyelitis. J Immunol. (2008) 180:2634-40. doi: 10.4049/jimmunol.180.4.2634

72. Tu L, Fang TC, Artis D, Shestova O, Pross SE, Maillard I, et al. Notch signaling is an important regulator of type 2 immunity. J Exp Med. (2005) 202:1037-42. doi: 10.1084/jem.20050923

73. Auderset F, Schuster S, Coutaz M, Koch U, Desgranges F, Merck E, et al. Redundant Notch 1 and Notch 2 signaling is necessary for IFN $\gamma$ secretion by T helper 1 cells during infection with leishmania major. PLoS Pathog. (2012) 8:e1002560. doi: 10.1371/journal.ppat. 1002560

74. Dongre A, Surampudi L, Lawlor RG, Fauq AH, Miele L, Golde TE, et al. Noncanonical Notch signaling drives activation and differentiation of peripheral CD4(+) T cells. Front Immunol. (2014) 5:54. doi: 10.3389/fimmu.2014.00054

75. Taleb S, Tedgui A, Mallat Z. IL-17 and Th17 cells in atherosclerosis: subtle and contextual roles. Arterioscler Thromb Vasc Biol. (2015) 35:258-64. doi: 10.1161/ATVBAHA.114.303567

76. Burkett PR, Meyer zu Horste G, Kuchroo VK. Pouring fuel on the fire: Th17 cells, the environment, and autoimmunity. J Clin Invest. (2015) 125:2211-9. doi: 10.1172/JCI78085
77. Eid RE, Rao DA, Zhou J, Lo SF, Ranjbaran H, Gallo A, et al. Interleukin-17 and interferon-gamma are produced concomitantly by human coronary artery-infiltrating $\mathrm{T}$ cells and act synergistically on vascular smooth muscle cells. Circulation. (2009) 119:1424-32. doi: 10.1161/CIRCULATIONAHA.108.827618

78. Damsker JM, Hansen AM, Caspi RR. Th1 and Th17 cells: adversaries and collaborators. Ann N Y Acad Sci USA. (2010) 1183:211-21. doi: 10.1111/j.1749-6632.2009.05133.x

79. Elyaman W, Bradshaw EM, Wang Y, Oukka M, Kivisäkk P, Chiba S, et al. JAGGED1 and deltal differentially regulate the outcome of experimental autoimmune encephalomyelitis. J Immunol. (2007) 179:5990-8.

80. Meng L, Hu S, Wang J, He S, Zhang Y. DLL4. Pharmacol Res. (2016) 113(Pt A):449-457. doi: 10.1016/j.phrs.2016.09.001

81. Mukherjee S, Schaller MA, Neupane R, Kunkel SL, Lukacs NW. Regulation of $\mathrm{T}$ cell activation by Notch ligand, DLL4, promotes IL17 production and rorc activation. J Immunol. (2009) 182:7381-8. doi: 10.4049/jimmunol.0804322

82. Meng L, Bai Z, He S, Mochizuki K, Liu Y, Purushe J, et al. The Notch ligand DLL4 defines a capability of human dendritic cells in regulating Th1 and Th17 differentiation. J Immunol. (2016) 196:1070-80. doi: 10.4049/jimmunol.1501310

83. Jiao Z, Wang W, Hua S, Liu M, Wang H, Wang X, et al. Blockade of Notch signaling ameliorates murine collagen-induced arthritis via suppressing Th1 and Th17 cell responses. Am J Pathol. (2014) 184:1085-93. doi: 10.1016/j.ajpath.2013.12.010

84. Meyer Zu Horste G, Wu C, Wang C, Cong L, Pawlak M, Lee Y, et al. RBPJ controls development of pathogenic Th17 cells by regulating IL-23 receptor expression. Cell Rep. (2016) 16:392-404. doi: 10.1016/j.celrep.2016.05.088

85. Wang Y, Xing F, Ye S, Xiao J, Di J, Zeng S, et al. Jagged-1 signaling suppresses the IL- 6 and TGF- $\beta$ treatment-induced Th17 cell differentiation via the reduction of ROR $\gamma \mathrm{t} / \mathrm{IL}-17 \mathrm{~A} / \mathrm{IL}-17 \mathrm{~F} / \mathrm{IL}-23 \mathrm{a} / \mathrm{IL}-12 \mathrm{rb1}$. Sci Rep. (2015) 5:8234. doi: $10.1038 /$ srep 08234

86. Zaman TS, Arimochi H, Maruyama S, Ishifune C, Tsukumo SI, Kitamura A, et al. Notch balances Th17 and induced regulatory $\mathrm{T}$ cell functions in dendritic cells by regulating. J Immunol. (2017) 199:1989-97. doi: 10.4049/jimmunol.1700645

87. Kaplan MH, Hufford MM, Olson MR. The development and in vivo function of T helper 9 cells. Nat Rev Immunol. (2015) 15:295-307. doi: $10.1038 /$ nri3824

88. Taleb S, Tedgui A. IL-9: a new culprit in atherosclerosis? Cardiovasc Res. (2015) 106:348-50. doi: 10.1093/cvr/cvv134

89. Elyaman W, Bassil R, Bradshaw EM, Orent W, Lahoud Y, Zhu $B$, et al. Notch receptors and Smad3 signaling cooperate in the induction of interleukin-9-producing t cells. Immunity. (2012) 36:623-34. doi: 10.1016/j.immuni.2012.01.020

90. Uyemura K, Demer LL, Castle SC, Jullien D, Berliner JA, Gately MK, et al. Cross-regulatory roles of interleukin (IL)-12 and IL-10 in atherosclerosis. $J$ Clin Invest. (1996) 97:2130-8. doi: 10.1172/JCI118650

91. Engelbertsen D, Rattik S, Knutsson A, Björkbacka H, Bengtsson E, Nilsson J. Induction of $\mathrm{T}$ helper 2 responses against human apolipoprotein B100 does not affect atherosclerosis in apoe ${ }^{-/-}$mice. Cardiovasc Res. (2014) 103:304-12. doi: 10.1093/cvr/cvu131

92. Zhao XN, Li YN, Wang YT. Interleukin-4 regulates macrophage polarization via the MAPK signaling pathway to protect against atherosclerosis. Genet Mol Res. (2016) 15. doi: 10.4238/gmr.15017348

93. King VL, Cassis LA, Daugherty A. Interleukin-4 does not influence development of hypercholesterolemia or angiotensin II-induced atherosclerotic lesions in mice. Am J Pathol. (2007) 171:2040-7. doi: 10.2353/ajpath.2007.060857

94. King VL, Szilvassy SJ, Daugherty A. Interleukin-4 deficiency decreases atherosclerotic lesion formation in a site-specific manner in female LDL receptor ${ }^{-/-}$mice. Arterioscler Thromb Vasc Biol. (2002) 22:456-61. doi: $10.1161 /$ hq0302.104905

95. Amsen D, Blander JM, Lee GR, Tanigaki K, Honjo T, Flavell RA. Instruction of distinct CD4 T helper cell fates by different Notch ligands on antigen-presenting cells. Cell. (2004) 117:515-26. doi: $10.1016 /$ S0092-8674(04)00451-9 
96. Tanaka S, Tsukada J, Suzuki W, Hayashi K, Tanigaki K, Tsuji M, et al. The interleukin- 4 enhancer CNS-2 is regulated by Notch signals and controls initial expression in NKT cells and memory-type CD4 T cells. Immunity. (2006) 24:689-701. doi: 10.1016/j.immuni.200 6.04 .009

97. Amsen D, Antov A, Jankovic D, Sher A, Radtke F, Souabni A, et al. Direct regulation of GATA-3 expression determines the T helper differentiation potential of Notch. Immunity. (2007) 27:89-99. doi: 10.1016/j.immuni.2007.05.021

98. Zheng W, Flavell RA. The transcription factor GATA-3 is necessary and sufficient for Th2 cytokine gene expression in CD4 T cells. Cell. (1997) 89:587-96

99. Fang TC, Yashiro-Ohtani Y, Del Bianco C, Knoblock DM, Blacklow SC, Pear WS. Notch directly regulates GATA-3 expression during $\mathrm{T}$ helper 2 cell differentiation. Immunity. (2007) 27:100-10. doi: 10.1016/j.immuni.2007.04.018

100. Xiong Y, Lingrel JB, Wüthrich M, Klein BS, Vasudevan NT, Jain MK, et al. Transcription factor KLF2 in dendritic cells downregulates Th2 programming via the HIF-1 $\alpha /$ Jagged2/Notch axis. MBio. (2016) 7. doi: 10.1128/mBio.00436-16

101. Tindemans I, Lukkes M, de Bruijn MJW, Li BWS, van Nimwegen M, Amsen D, et al. Notch signaling in $\mathrm{T}$ cells is essential for allergic airway inflammation, but expression of the Notch ligands jagged 1 and jagged 2 on dendritic cells is dispensable. J Allergy Clin Immunol. (2017) 140:1079-89. doi: 10.1016/j.jaci.2016.11.046

102. Damle SR, Martin RK, Cockburn CL, Lownik JC, Carlyon JA, Smith $\mathrm{AD}$, et al. ADAM10 and Notch1 on murine dendritic cells control the development of type 2 immunity and IgE production. Allergy. (2018) 73:12536. doi: 10.1111/all.13261

103. Ou HX, Guo BB, Liu Q, Li YK, Yang Z, Feng WJ, et al. Regulatory T cells as a new therapeutic target for atherosclerosis. Acta Pharmacol Sin. (2018). 39:1249-58. doi: 10.1038/aps.2017.140

104. Foks AC, Lichtman AH, Kuiper J. Treating atherosclerosis with regulatory T cells. Arterioscler Thromb Vasc Biol. (2015) 35:280-7. doi: 10.1161/ATVBAHA.114.303568

105. Pastrana JL, Sha X, Virtue A, Mai J, Cueto R, Lee IA, et al. (2012). Regulatory T cells and atherosclerosis. J Clin Exp Cardiolog. 2012:2. doi: 10.4172/2155-9880.S12-002

106. de Boer OJ, van der Meer JJ, Teeling PCM, van der Loos, van der Wal AC. Low numbers of FOXP3 positive regulatory $\mathrm{T}$ cells are present in all developmental stages of human atherosclerotic lesions. PLoS ONE. (2007) 2:e779. doi: 10.1371/journal.pone.0000779

107. Rohm I, Atiskova Y, Drobnik S, Fritzenwanger M, Kretzschmar D, Pistulli $\mathrm{R}$, et al. Decreased regulatory $\mathrm{T}$ cells in vulnerable atherosclerotic lesions: imbalance between pro- and anti-inflammatory cells in atherosclerosis. Mediators Inflamm. (2015) 2015:364710. doi: 10.1155/2015/364710

108. Dietel B, Cicha I, Voskens CJ, Verhoeven E, Achenbach S, Garlichs $\mathrm{CD}$. Decreased numbers of regulatory $\mathrm{T}$ cells are associated with human atherosclerotic lesion vulnerability and inversely correlate with infiltrated mature dendritic cells. Atherosclerosis. (2013) 230:92-9. doi: 10.1016/j.atherosclerosis.2013.06.014

109. Ait-Oufella H, Salomon BL, Potteaux S, Robertson AK, Gourdy P, Zoll J, et al. Natural regulatory $\mathrm{T}$ cells control the development of atherosclerosis in mice. Nat Med. (2006) 12:178-80. doi: 10.1038/nm1343

110. Meng X, Li W, Yang J, Zhang K, Qin W, An G, et al. Regulatory T cells prevent plaque disruption in apolipoprotein E-knockout mice. Int J Cardiol. (2013) 168:2684-92. doi: 10.1016/j.ijcard.2013.03.026

111. Grazioli P, Felli MP, Screpanti I, Campese AF. The mazy case of Notch and immunoregulatory cells. J Leukoc Biol. (2017) 102:361-8. doi: 10.1189/jlb.1VMR1216-505R

112. Ostroukhova M, Qi Z, Oriss TB, Dixon-McCarthy B, Ray P, Ray A. Treg-mediated immunosuppression involves activation of the Notch-HES1 axis by membrane-bound TGF-beta. J Clin Invest. (2006) 116:996-1004. doi: 10.1172/JCI26490

113. Huang MT, Chen YL, Lien CI, Liu WL, Hsu LC, Yagita H, et al. Notch ligand DLL4 alleviates allergic airway inflammation via induction of a homeostatic regulatory pathway. Sci Rep. (2017) 7:43535. doi: 10.1038/sre p43535
114. Lin Y, Chen W, Li J, Yan G, Li C, Jin N, et al. Overexpression of Jagged1 combined with blockade of CD40 pathway prolongs allograft survival. Immunol Cell Biol. (2015) 93:213-7. doi: 10.1038/icb.2014.84

115. Campese AF, Grazioli P, Colantoni S, Anastasi E, Mecarozzi M, Checquolo $\mathrm{S}$, et al. Notch3 and pTalpha/pre-TCR sustain the in vivo function of naturally occurring regulatory $\mathrm{T}$ cells. Int Immunol. (2009) 21:727-43. doi: 10.1093/intimm/dxp042

116. Anastasi E, Campese AF, Bellavia D, Bulotta A, Balestri A, Pascucci M, et al. Expression of activated Notch3 in transgenic mice enhances generation of $\mathrm{t}$ regulatory cells and protects against experimental autoimmune diabetes. $J$ Immunol. (2003) 171:4504-11. doi: 10.4049/jimmunol.171.9.4504

117. Butcher MJ, Filipowicz AR, Waseem TC, McGary CM, Crow KJ, Magilnick $\mathrm{N}$, et al. Atherosclerosis-driven treg plasticity results in formation of a dysfunctional subset of plastic IFN $\gamma+$ Th1/Tregs. Circ Res. (2016) 119:1190203. doi: 10.1161/CIRCRESAHA.116.309764

118. Li J, McArdle S, Gholami A, Kimura T, Wolf D, Gerhardt T, et al. CCR5+Tbet+FoxP3+ effector CD4 T cells drive atherosclerosis. Circ Res. (2016) 118:1540-52. doi: 10.1161/CIRCRESAHA.116.308648

119. Charbonnier LM, Wang S, Georgiev P, Sefik E, Chatila TA. Control of peripheral tolerance by regulatory $\mathrm{T}$ cell-intrinsic Notch signaling. Nat Immunol. (2015) 16:1162-73. doi: 10.1038/ni.3288

120. Rong H, Shen H, Xu Y, Yang H. Notch signalling suppresses regulatory T-cell function in murine experimental autoimmune uveitis. Immunology. (2016) 149:447-59. doi: 10.1111/imm. 12663

121. Joffre OP, Segura E, Savina A, Amigorena S. Cross-presentation by dendritic cells. Nat Rev Immunol. (2012) 12:557-69. doi: 10.1038/nri3254

122. Cochain C, Zernecke A. Protective and pathogenic roles of CD8. Basic Res Cardiol. (2016) 111:71. doi: 10.1007/s00395-016-0589-7

123. Jonasson L, Holm J, Skalli O, Bondjers G, Hansson GK. Regional accumulations of $\mathrm{T}$ cells, macrophages, and smooth muscle cells in the human atherosclerotic plaque. Arteriosclerosis. (1986) 6:131-8.

124. Kolbus D, Ljungcrantz I, Andersson L, Hedblad B, Fredrikson GN, Björkbacka $\mathrm{H}$, et al. Association between CD8+ T-cell subsets and cardiovascular disease. J Intern Med. (2013) 274:41-51. doi: 10.1111 /joim. 12038

125. van Duijn J, Kuiper J, Slütter B. The many faces of CD8+ $\mathrm{T}$ cells in atherosclerosis. Curr Opin Lipidol. (2018) 29:411-6. doi: 10.1097/MOL.0000000000000541

126. Wong KK, Carpenter MJ, Young LL, Walker SJ, McKenzie G, Rust AJ, et al. Notch ligation by deltal inhibits peripheral immune responses to transplantation antigens by a CD8+ cell-dependent mechanism. J Clin Invest. (2003) 112:1741-50. doi: 10.1172/JCI18020

127. Palaga T, Miele L, Golde TE, Osborne BA. TCR-mediated Notch signaling regulates proliferation and IFN-gamma production in peripheral T cells. $J$ Immunol. (2003) 171:3019-24. doi: 10.4049/jimmunol.171.6.3019

128. Cho OH, Shin HM, Miele L, Golde TE, Fauq A, Minter LM, et al. Notch regulates cytolytic effector function in CD8+ T cells. J Immunol. (2009) 182:3380-9. doi: 10.4049/jimmunol.0802598

129. Kuijk LM, Verstege MI, Rekers NV, Bruijns SC, Hooijberg E, Roep BO, et al. Notch controls generation and function of human effector CD8+ T cells. Blood. (2013) 121:2638-46. doi: 10.1182/blood-2012-07-442962

130. Maekawa Y, Minato Y, Ishifune C, Kurihara T, Kitamura A, Kojima H, et al. Notch2 integrates signaling by the transcription factors RBP-J and CREB1 to promote T cell cytotoxicity. Nat Immunol. (2008) 9:1140-7. doi: 10.1038/ni.1649

131. Backer RA, Helbig C, Gentek R, Kent A, Laidlaw BJ, Dominguez CX, et al. A central role for Notch in effector CD8(+) T cell differentiation. Nat Immunol. (2014) 15:1143-51. doi: 10.1038/ni.3027

132. Amsen D, Helbig C, Backer RA. Notch in T cell differentiation: all things considered. Trends Immunol. (2015) 36:802-14. doi: 10.1016/j.it.2015. 10.007

133. Veglia F, Perego M, Gabrilovich D. Myeloid-derived suppressor cells coming of age. Nat Immunol. (2018) 19:108-19. doi: 10.1038/s41590-0170022-x

134. Foks AC, Van Puijvelde GH, Wolbert J, Kröner MJ, Frodermann VT, Van Der Heijden, Van Santbrink PJ, et al. CD11 $\mathrm{b}^{+} \mathrm{Gr}-1^{+}$myeloid-derived suppressor cells reduce atherosclerotic lesion development in LDLr deficient mice. Cardiovasc Res. (2016) 111:252-61. doi: 10.1093/cvr/cvw114 
135. Wang YG, Xiong X, Chen ZY, Liu KL, Yang JH, Wen Q, et al. Expansion of myeloid-derived suppressor cells in patients with acute coronary syndrome. Cell Physiol Biochem. (2015) 35:292-304. doi: 10.1159/000369696

136. Gibb DR, Saleem SJ, Kang DJ, Subler MA, Conrad DH. ADAM10 overexpression shifts lympho- and myelopoiesis by dysregulating site 2/site 3 cleavage products of Notch. J Immunol. (2011) 186:4244-52. doi: 10.4049/jimmunol.1003318

137. Sierra RA, Trillo-Tinoco J, Mohamed E, Yu L, Achyut BR, Arbab A, et al. Anti-jagged immunotherapy inhibits MDSCs and overcomes tumor-induced tolerance. Cancer Res. (2017) 77:5628-38. doi: 10.1158/0008-5472.CAN-17-0357

138. Hossain F, Majumder S, Ucar DA, Rodriguez PC, Golde TE, Minter LM, et al. Notch signaling in myeloid cells as a regulator of tumor immune responses. Front Immunol. (2018) 9:1288. doi: 10.3389/fimmu.2018.01288

139. Vijayaraghavan J, Osborne BA. Notch and $\mathrm{T}$ cell function-a complex tale. Adv Exp Med Biol. (2018) 1066:339-54. doi: 10.1007/978-3-319-89512-3_17

140. Rizzo P, Osipo C, Foreman K, Golde T, Osborne B, Miele L. Rational targeting of Notch signaling in cancer. Oncogene. (2008) 27:5124-31. doi: 10.1038/onc.2008.226

141. Gu K, Li Q, Lin H, Zhu J, Mo J, He S, et al. Gamma secretase inhibitors: a patent review (2013-2015). Expert Opin Ther Pat. (2017) 27:851-66. doi: 10.1080/13543776.2017.1313231

142. Mamaeva V, Niemi R, Beck M, Özliseli E, Desai D, Landor S, et al. Inhibiting Notch Activity in Breast Cancer Stem Cells by Glucose Functionalized Nanoparticles Carrying $\gamma$-secretase Inhibitors. Mol Ther. (2016) 24:926-36. doi: $10.1038 / \mathrm{mt} .2016 .42$

143. Miranda K, Yang X, Bam M, Murphy EA, Nagarkatti PS, Nagarkatti M. MicroRNA-30 modulates metabolic inflammation by regulating Notch signaling in adipose tissue macrophages. Int J Obes. (2018) 42:1140-50. doi: 10.1038/s41366-018-0114-1

144. Barile L, Vassalli G. Exosomes: therapy delivery tools and biomarkers of diseases. Pharmacol Ther. (2017) 174:63-78. doi: 10.1016/j.pharmthera.2017.02.020

145. Caolo V, Schulten HM, Zhuang ZW, Murakami M, Wagenaar A, Verbruggen $\mathrm{S}$, et al. Soluble jagged-1 inhibits neointima formation by attenuating Notch-herp2 signaling. Arterioscler Thromb Vasc Biol. (2011) 31:1059-65. doi: 10.1161/ATVBAHA.110.217935

146. Hossain F, Ucar D, Majumder S, Xu K, Ran Y, Minter L, et al. Repurposing sulindac sulfide as a Notch inhibitor to target cancer stem-like cells in triple negative breast cancer. In: AACR\&C. Res. editor. San Antonio Breast
Cancer Symposium (Philadelphia, PA). doi: 10.1158/1538-7445.SABCS18P6-22-01

147. Aquila G, Fortini C, Pannuti A, Delbue S, Pannella M, Morelli MB, et al. Distinct gene expression profiles associated with Notch ligands delta-like 4 and jagged 1 in plaque material from peripheral artery disease patients: a pilot study. J Transl Med. (2017) 15. doi: 10.1186/s12967-017-1199-3

148. Yan M, Callahan CA, Beyer JC, Allamneni KP, Zhang G, Ridgway JB, et al. Chronic DLL4 blockade induces vascular neoplasms. Nature. (2010) 463:E6-7. doi: 10.1038/nature08751

149. Smith DC, Eisenberg PD, Manikhas G, Chugh R, Gubens MA, Stagg RJ, et al. A phase I dose escalation and expansion study of the anticancer stem cell agent demcizumab (anti-DLL4) in patients with previously treated solid tumors. Clin Cancer Res. (2014) 20:6295-303. doi: 10.1158/1078-0432.CCR14-1373

150. Bullenkamp J, Dinkla S, Kaski JC, Dumitriu IE, Targeting $\mathrm{T}$ cells to treat atherosclerosis: odyssey from bench to bedside. Eur Heart J Cardiovasc Pharmacother. (2016) 2:194-9. doi: 10.1093/ehjcvp/ pvw001

151. Kelliher MA, Roderick JE. NOTCH signaling in T-cell-mediated antitumor immunity and T-cell-based immunotherapies. Front Immunol. (2018) 9:1718. doi: 10.3389/fimmu.2018.01718

152. Fortini F, Vieceli Dalla Sega F, Caliceti C, Lambertini E, Pannuti A, Peiffer DS, et al. Estrogen-mediated protection against coronary heart disease: the role of the Notch pathway. J Steroid Biochem Mol Biol. (2019) 189:87-100. doi: 10.1016/j.jsbmb.2019.02.008

153. Aday AW, Ridker PM. Antiinflammatory therapy in clinical care: the CANTOS trial and beyond. Front Cardiovasc Med. (2018) 5:62. doi: $10.3389 /$ fcvm.2018.00062

Conflict of Interest Statement: The authors declare that the research was conducted in the absence of any commercial or financial relationships that could be construed as a potential conflict of interest.

Copyright $(\odot) 2019$ Vieceli Dalla Sega, Fortini, Aquila, Campo, Vaccarezza and Rizzo. This is an open-access article distributed under the terms of the Creative Commons Attribution License (CC BY). The use, distribution or reproduction in other forums is permitted, provided the original author(s) and the copyright owner(s) are credited and that the original publication in this journal is cited, in accordance with accepted academic practice. No use, distribution or reproduction is permitted which does not comply with these terms. 